\title{
First record of upside-down jellyfish Cassiopea andromeda (Forskål, 1775) (Cnidaria: Scyphozoa: Rhizostomeae: Cassiopeidae) from Sri Lanka
}

\author{
Krishan D. Karunarathne, Shanika M. Liyanaarachchi and M.D.S.T. de Croos* \\ Department of Aquaculture and Fisheries, Faculty of Livestock, Fisheries and Nutrition, \\ Wayamba University of Sri Lanka, Makandura, Gonawila (NWP), 60170, Sri Lanka. \\ *Correspondence (dileepa_dc@yahoo.com,dileepad@wyb.ac.lk) \\ hhttps://orcid.org/0000-0003-4449-6573
}

Received: 28.03.2020 Revised: 03.09.2020 Accepted: 04.09.2020 Published online: 15.09.2020

\begin{abstract}
The circumtropical upside-down jellyfish Cassiopea andromeda is native to the Indian region, but no scientific documentations are confirming its presence in Sri Lankan waters. Hence in this paper, the occurrence of $C$. andromeda in Sri Lankan waters is reported for the first time. Species identification was based on several specimens collected from shallow waters of north and east coasts of the country in 2017. The $C$. andromeda found from Sri Lanka is a mild stinger and so far there are no reports on severe health issues cause to fishers and tourists. Also, this species was identified as a potential ornamental species due to its gorgeous appearance with very high colour variation.
\end{abstract}

Keywords: Benthos, coastal waters, invasiveness, medusae, zooxanthellae

\section{INTRODUCTION}

Scyphomedusae, generally called as 'true jellyfish', directly interfere with many human activities through stings, clogging intakes, interference with fishing and aquaculture (Purcell et al. 2007; Richardson et al. 2009). The role of jellyfish as predators on fish eggs and larvae, vectors for parasites, and as shelter or food for some juvenile fish species have been reviewed by Purcell and Arai (2001), but both negative and positive influences of jellyfish on global fisheries are difficult to be quantified. Some jellyfish provide benefits for humans (reviewed by Purcell et al. 2007), especially as food (Hsieh et al. 2001), and as a source of extracting valuable chemical compounds (Sugahara et al. 2006; Ohta et al. 2009).

So far 200-300 species of scyphomedusae have been reported around the world. Of them, jellyfish with subumbrellar muscles in featherlike arcs belong to a single-family Cassiopeidae that is also a monotypic taxon comprising of the genus Cassiopea (Kramp 1961). Ten species have been classified into the genus Cassiopea (Kramp 1961; Hummelinck 1968; Thiel 1975; WoRMS Editorial Board 2020); and they show different colour morphs due to the colour producing dinoflagellate algae (zooxanthellae) that live within them symbiotically for photosynthesis (Rahat and Adar 1980; Lampert et al. 2012; Lampert 2016). The Cassiopea species are beneficial for humans; for examples, Cassiopea ndrosia Agassiz \& Mayer, 1899 is considered a delicacy in the Philippines (Omori and Nakono 2001) and Cassiopea maremetens Gershwin, Zeidler \& Davie, 2010 as a potential biomonitor in detecting effects of herbicide runoff (McKenzie et al. 2020).

The tropical Indo-Pacific region is a biodiversity hotspot for these cassiopeids (Schembri et al. 2010), which most often occur in shallow bays, intertidal sands, mangrove mudflats and lagoons (Browne 1916). Cassiopea andromeda (Forskål, 1775) is a common upsidedown jellyfish originally reported from the Red Sea, but now it has been reported as an invasive or alien species around the world (Galil et al. 1990; Zenetos et al. 2005, 2011; Çevik et al. 2006; Özgür and Öztürk 2008; Schembri et al. 2010; Katsanevakis 2011; Gülşahin and Tarkan 2012), therefore, it referred as ecologically important species by concerning its invasive distribution (Heins et al. 2015). 


\section{Krishan D. Karunarathne et al.}

Being a tropical island between the Arabian Sea and the Bay of Bengal, Sri Lanka has become one of the marine biodiversity hotspots in the Indian Ocean. Several marine expeditions have been carried out in the exclusive economic zone (EEZ) of Sri Lanka during the last two centuries, but only a considerable number of nonscyphozoan jellyfish species have been reported so far. For example, Kramp (1965) reported around 35 species of hydromedusae collected within Sri Lankan EEZ through the Dana Expedition and Galathea II Expedition led respectively in 1928-30 and 1950-52. However, due to lack of taxonomic studies, knowledge on the scyphozoan jellyfish which dwell in Sri Lankan waters is poor (Karunarathne and de Croos 2020a). Haeckel (1883) initiated the taxonomic studies of Sri Lankan scyphomedusae; and described a rhizostome jellyfish species Toreuma bellagemma found from Weligama (Belligemma - Ceylon) in December 1881 (Haeckel 1904). The genus Toreuma was classified together with Casssiopea under a same family by Haeckel (1879), but the genus Toreuma and related species are doubtful.

Stiasny (1931), Fernando (2006), and Karunarathne and de Croos (2020b) worked on the taxonomic identification of five other rhizostome jellyfish species namely, Cephea cephea (Forskål, 1775), Crambione mastigophora Maas, 1903, Lychnorhiza malayensis Stiasny, 1920, Marivagia stellata Galil \& Gershwin, 2010, and Netrostoma setouchianum (Kishinouye, 1902), which were reported in Sri Lankan waters. Two individuals of Cassiopea (YPM IZ 007099.CN) collected from Point Elizabeth, North of Trincomalee, Sri Lanka through the Yale Seychelles Expedition (1957-58), and five other Cassiopea specimens (NHMUK 1946.3.1.6-10), which were collected from Karaitivu and Mutwal islands, Portugal Bay off Kalpitiya, Sri Lanka have been housed in the Yale Peabody Museum, and in the Natural History Museum, London respectively (Gall 2020; Natural History Museum 2020); however, they were documented only up to the genus level. Therefore, in this study we report the Sri Lankan upside-down jellyfish species as Cassiopea andromeda for the first time, by taxonomic examining of specimens obtained from different localities of the country.

\section{MATERIALS AND METHODS}

A year-round, systematic jellyfish survey was carried out from March 2017 to April 2018 in identifying the species which found in the coastal waters of Sri Lanka. In 2017, upside-down jellyfish were observed in coastal waters of the northeast, north, and east Sri Lanka, and they were photographed in situ to record their colour variations while, altogether 23 specimens were randomly collected from north and east coasts (Fig. 1) by using a scoop net (mesh size $5 \mathrm{~mm}$ ). The bell diameter of each specimen was measured to the nearest millimeter, using a plastic ruler, and preserved in a solution of 5\% formalin in seawater.

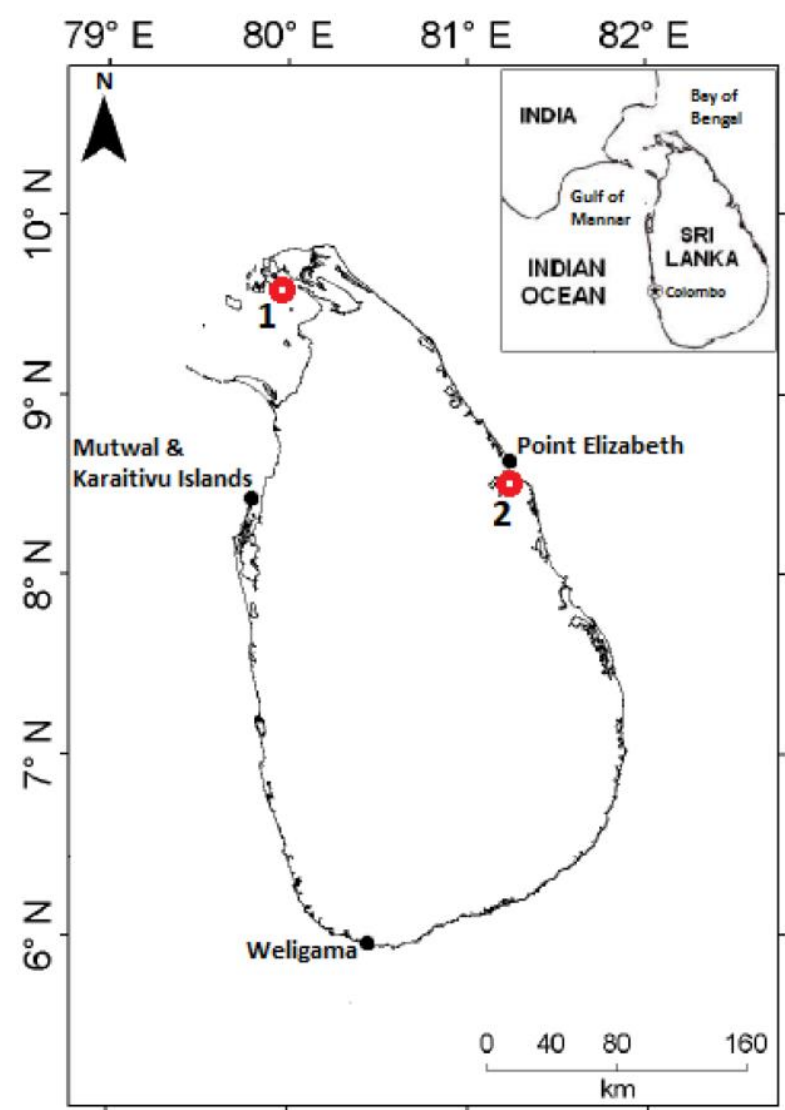

Fig 1 Localities where the upside-down jellyfish specimens were collected in coastal waters of Sri Lanka for the present study (indicated by open circles): 1 - Jaffna; 2 - Trincomalee. Inset shows the location of Sri Lanka in the Indian Ocean.

The morphological examination and taxonomic identification of these specimens were carried out at the laboratory following Mayer (1910), Kramp (1961), and Morandini et al. (2017). After the identification, all the specimens were kept in the Museum of Department of Aquaculture and Fisheries, Wayamba University of Sri Lanka (MDAFWU) by providing accession numbers.

Additionally, eight water quality parameters (temperature, dissolved oxygen, $\mathrm{pH}$, salinity, 
Krishan D. Karunarathne et al.

total dissolved solids, electrical conductivity, resistivity, and turbidity) of sampling locations were measured by using a digital multiparameter instrument (HACH HQ $40 \mathrm{D}$ ), and a hand-held turbidity meter (HACH 2100P). Coordinates of sampling locations were recorded with a GPS machine (GARMIN 72H).

\section{RESULTS}

Material examined: 13 specimens (MDAFWU 2017/36-48), Kaakkai Thevu - Jaffna (9.6887 ${ }^{\circ} \mathrm{N}$, 79.9959 ${ }^{\circ}$ ), coll. in March 2017., 9 specimens (MDAFWU 2017/99-100, 116-122), Pannei Jaffna $\left(9.6427^{\circ} \mathrm{N}, 79.9905^{\circ} \mathrm{E}\right)$, May \& August 2017., 1 specimen (MDAFWU 2017/246), Inner
Harbour - Trincomalee $\left(8.5720^{\circ} \mathrm{N}, 81.1942^{\circ} \mathrm{E}\right)$, December 2017.

\section{Systematics of Sri Lankan upside-down jellyfish:}

Phylum Cnidaria Verrill, 1865

Subphylum Medusozoa Petersen, 1979

Class Scyphozoa Götte, 1887

Order Rhizostomeae Cuvier, 1800

Suborder Kolpophorae Stiasny, 1920

Infraorder Kampylomyaria Stiasny, 1920

Family Cassiopeidae Tilesius, 1831

Genus Cassiopea Péron \& Lesueur, 1810

Species Cassiopea andromeda (Forskål, 1775)

(Figs. 2-4)
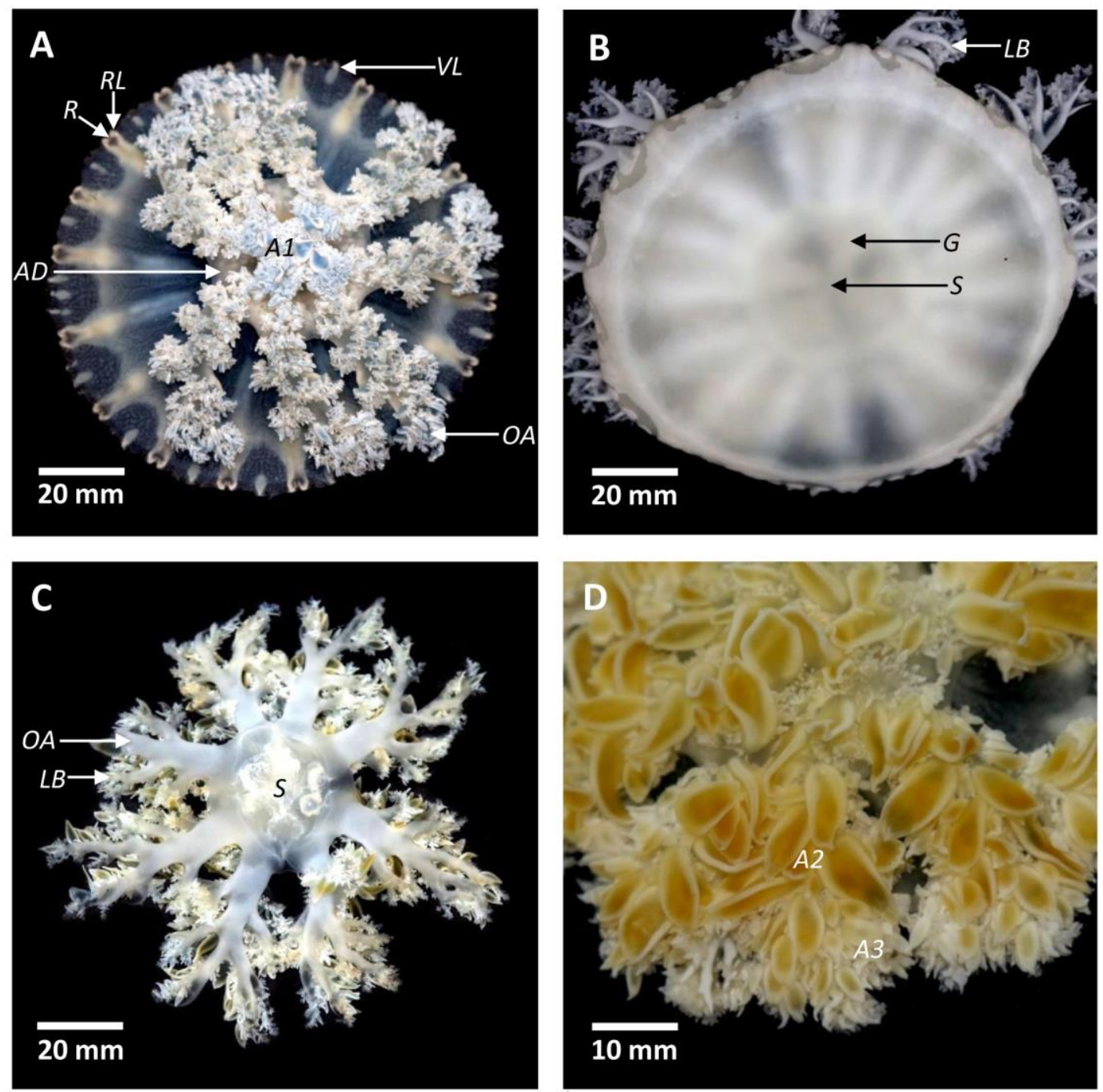

Fig 2 External features of Cassiopea andromeda (A-D): subumbrellar view (A); exumbrellar view (B); aboral view of separated oral arms from bell (note the arrangement of lateral branches) (C); close view of leaf-shaped appendages on oral arms (note the absence of filaments) (D). Al - large appendages on arm disc; $A 2$ - large appendages on oral arms; $A 3$ - small appendages on oral arms; $A D$ - arm disc; $G$ gonads; $L B$ - lateral branch of oral arm; $O A$ - oral arm; $R$ - rhopalium; $R L$ - rhopalar lappet; $S$ - stomach region; VL - velar lappets. 
Description: Umbrella up to $210 \mathrm{~mm}$ in diameter, flat and disc-shaped, without a central concavity or dome (Fig. 2B). Center of exumbrellar surface smooth, peripheral partially rough. Arm disc about one-third of umbrella in diameter, with five or more flat, leaf-shaped, up to $20 \mathrm{~mm}$ long appendages arising from the middle (Fig. 2A). Oral arms 8, wide, flat in crosssection, as long as or slightly longer than umbrella radius (Fig. 2A, B); bearing 4-6 alternately arranged, lateral branches, shorter proximally, longer distally, with the central trunk ending in a bifurcation (Fig. 2C). Flat, leafshaped appendages arranged along each oral arm, similar or smaller in size to those on the arm disc; filaments absent (Fig. 2A, D). Mouthlets arranged in a crowded manner along the oral edge of all arms and branches. Rhopalia 15-23 (mostly 16 or 17); each rhopalar lappet flanked by similar-sized, blunt, 3-6 velar lappets (Fig. $2 \mathrm{~A})$; thus, a total of 5-8 lappets between successive rhopalia. Lappets demarcated near the margin of the exumbrella by permanent furrows. Subumbrellar surface as a repeating pattern of fine V-shaped muscle bands (Fig. 2A). Stomach small, about one-fourth the diameter of the disc (Fig. 2B, C). Gonads entirely enclosed by the stomach. Ring canal absent. Colour in life variable in the population (mostly brown with paler spots; however, several colour morphs reported from milky white to purple) (Fig. 3A$\mathrm{H})$.

Local names: Mada Horiya (in Sinhalese); Seru Soriyan (in Tamil).

Habitats in Sri Lanka: Shallow, calm, both marine and brackish waters (depth: near-surface to $5 \mathrm{~m}$ ). Usually inverted on muddy and rocky bottoms and swims occasionally (Fig. 4A, B). Abundance is very high in polluted (dumping) areas with nutrients. Temperature $25.7-34.7^{\circ} \mathrm{C}$, dissolved oxygen 4.4-9.4 ppm, pH 6.4-8.2, salinity $25.8-39.7 \mathrm{ppt}$, total dissolved solids 24.5-37.7 ppt, electrical conductivity 43.6-73.1 $\mathrm{ms} / \mathrm{cm}$, resistivity $16.8-25.1 \Omega / \mathrm{cm}$, and turbidity 2.7-29.3 NTU.
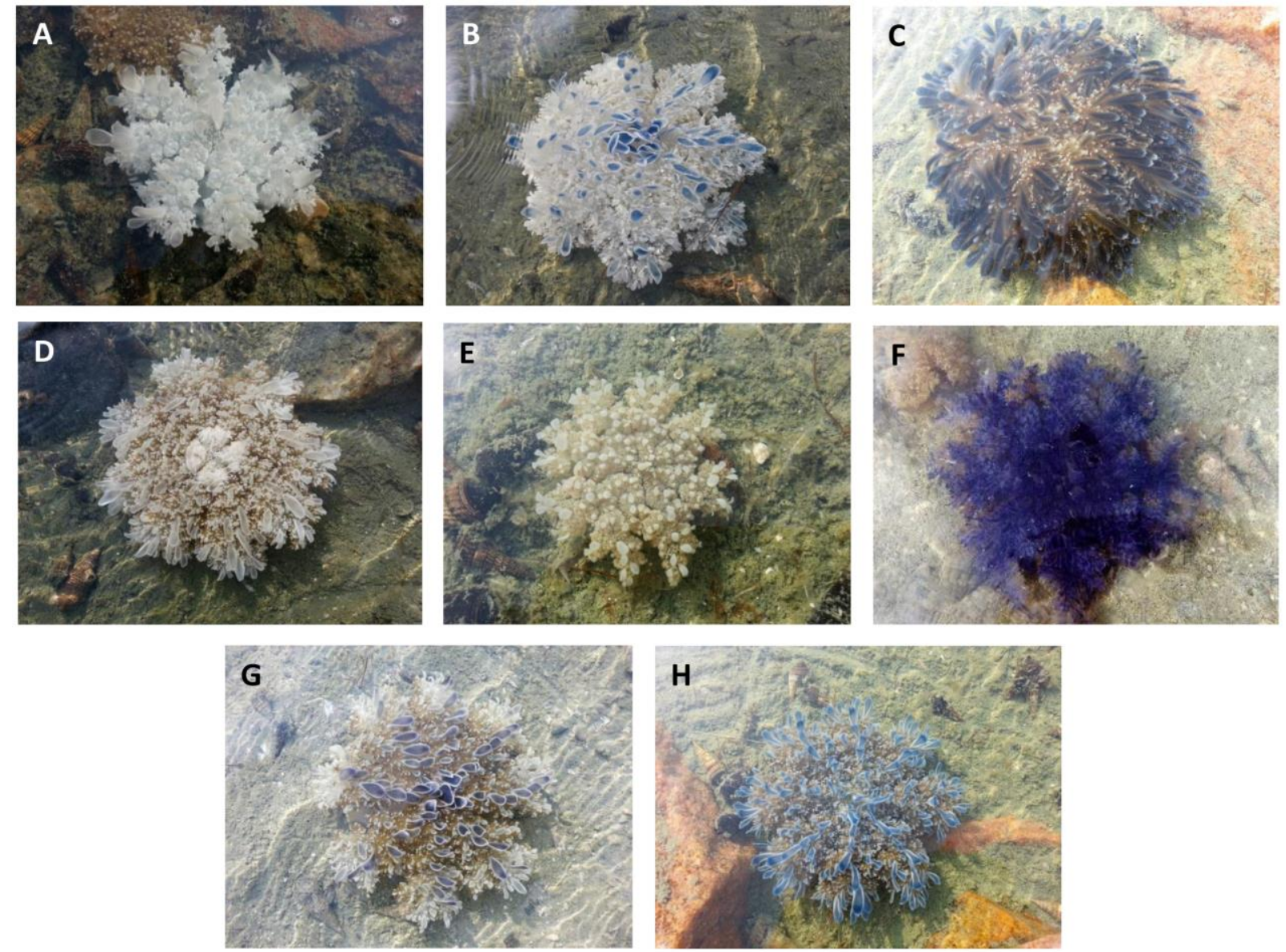

Fig 3 Some colour morphs of live Cassiopea andromeda observed in the northern Sri Lanka (A-H). 

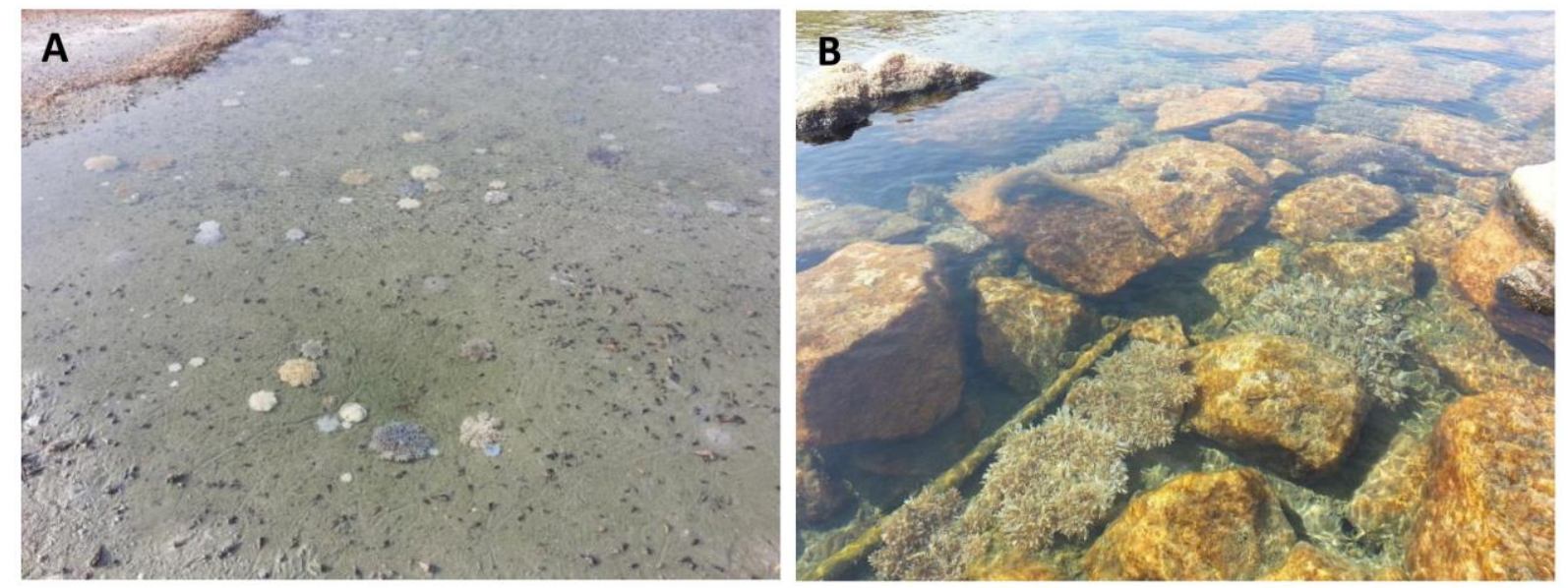

Fig 4 Accumulations of Cassiopea andromeda on muddy bottom (A) and rocky bottom (B) in the Jaffna Lagoon, Sri Lanka.

\section{DISCUSSION}

For the first time we report the occurrence of Cassiopea andromeda in Sri Lankan waters even though it has been native to the Indian region. Holland et al. (2004) and Morandini et al. (2017) studied phylogeography and molecular systematics of currently recognized Cassiopea species from several regions of the world by obtaining sequences of mitochondrial gene COI. These molecular phylogenetic results provisioned for the identification of the Red Sea populations as $C$. andromeda. Also, this medusa was morphologically identified and reported previously in India as $C$. andromeda var. maldivensis by Browne (1916) and Rao (1931); and as C. andromeda by Menon (1930, 1936), Venkataraman et al. (2012), and Prasade et al. (2016). Records on the Gulf of Mannar belong to Indian waters are out from Sri Lankan EEZ. Waters of the Red Sea and the Arabian Sea are greatly mixed up by the combined effects of southwest monsoon currents, northeast monsoon currents, West India coastal currents and Somali currents (Kimor 1973; Shenoi et al. 1999); therefore, the west coast of Sri Lanka can considerably represent the marine biodiversity which exists in the Red Sea and west coast of India. As such, the dispersion of $C$. andromeda in Sri Lankan waters is highly possible with the water currents which occur towards the Gulf of Mannar. Even though there are no any scientific reports on the occurrence of this medusa, the local fishermen have observed this species for decades in the coastal waters of Sri Lanka (pers. comm. with traditional trap-net fishers).

Morandini et al. (2017) showed that the distribution of $C$. andromeda is extended up to
Florida, Bermuda, Brazil (the Atlantic Ocean) and Hawaii (the Pacific Ocean). Not only in the tropical region, but even in the Mediterranean waters $C$. andromeda has been reported as an invasive or alien species (Galil et al. 1990; Çevik et al. 2006; Özgür and Öztürk 2008; Schembri et al. 2010; Gülşahin and Tarkan 2012). Schäffer (1955) reported that the juvenile $C$. andromeda was abundant in rock pools of the Aegean Sea where the water temperature reached $36^{\circ} \mathrm{C}$; and, Çevik et al. (2006) sampled $C$. andromeda on a muddy sandy bottom in Turkish waters where the temperature was $34^{\circ} \mathrm{C}$, salinity $38.51 \mathrm{ppt}$, dissolved oxygen $5.4 \mathrm{ppm}$, and $\mathrm{pH}$ 8.02. During this study, Sri Lankan specimens were found on both rocky and muddy bottoms (Fig. 4A, B) while, the water temperature of the habitat ranged from 25.7 to $34.7^{\circ} \mathrm{C}$ within the mean water temperature of Turkish waters $\left(23^{\circ} \mathrm{C}\right.$ in winter and $36^{\circ} \mathrm{C}$ in summer) (referring Çevik et al. 2006). The type locality of $C$. andromeda (the Red Sea) has higher water temperatures, but the tolerability of a wide range of temperature (25.7$36.0^{\circ} \mathrm{C}$ ) would mostly lead this species for its reported invasive distribution in warm waters according to the results of the present study and Schäffer's (1955) data. Moreover, as noticed in this study, the tolerance for a wider salinity range $(25.8-39.7$ ppt $)$ may also support the dissemination of this species around the worlds' seas.

According to Mayer (1910) and Kramp (1961), bell size of $C$. andromeda is up to 120 $\mathrm{mm}$. But Morandini et al. (2017) reported the bell size up to $200 \mathrm{~mm}$ from Brazilian specimens, which are close to the range in size with the specimens found in the current study. The number of rhopalia (15-23) per medusa observed 
in Sri Lankan specimens are also closer to the respective range (16-22) in specimens inspected by Morandini et al. (2017). According to the original plate of $C$. andromeda, the count of rhopalia per medusa is sixteen (Fig. 5A). But Toreuma bellagemma which has been described from Sri Lankan waters by Haeckel (1904) has only eight rhopalia (Fig. 5B) therefore, $T$. bellagemma is clearly be distinguished from $C$. andromeda. Moreover, T. bellagemma owns a warty exumbrella with a central dome while, the umbrella is flat and the center of the exumbrellar surface is smooth in C. andromeda (Fig. 5A, B).

As observed in the present study, in Sri Lankan juvenile $C$. andromeda, each rhopalar lappet usually flanked by minimum three, blunt velar lappets; therefore, altogether five lappets are among successive rhopalia. While the medusa is getting matured, each velar lappet divides into two, forming up to six lappets (altogether eight lappets among successive rhopalia). Likewise, the total number of velar lappets and the total number of both types of lappets (velar + rhopalar) per medusa found in Sri Lankan waters were 45-90 and 60-120 respectively. According to Kramp (1961), Cassiopea depressa Haeckel, 1880 is only the other upside-down jellyfish species reported in the Indian Ocean and is clearly be distinguished from $C$. andromeda, due to the possession of 144 , wide, pointed lappets and vary small, leaf-shaped appendages between the mouths. In Sri Lankan specimens, both small and large appendages were found among mouths (Fig. 2D). The distribution of C. depressa is between Madagascar and Mozambique (Kramp 1961), which is far away from the Arabian Sea where $C$. andromeda is generally distributed.

Lampert et al. (2012) found six different colour morphs of $C$. andromeda, viz. red, brown, white, green, blue, purple from the Red Sea. During the present study most of these colour morphs could be found in Sri Lankan $C$. andromeda as well (Fig. 3A-H). Cassiopea frondosa (Pallas, 1774) is exhibited in zoos and aquariums (AZA 2013) similarly, wild-collected upside-down jellyfish were found to be displayed in some public aquariums in Sri Lanka (authors' observations). There would be a good potential to enhance the Sri Lankan marine aquarium industry with cultured, local Cassiopea because of their gorgeous colour variations; however, further studies should be carried out to keep their natural colours under artificial conditions in developing aquaculture techniques. Evan the
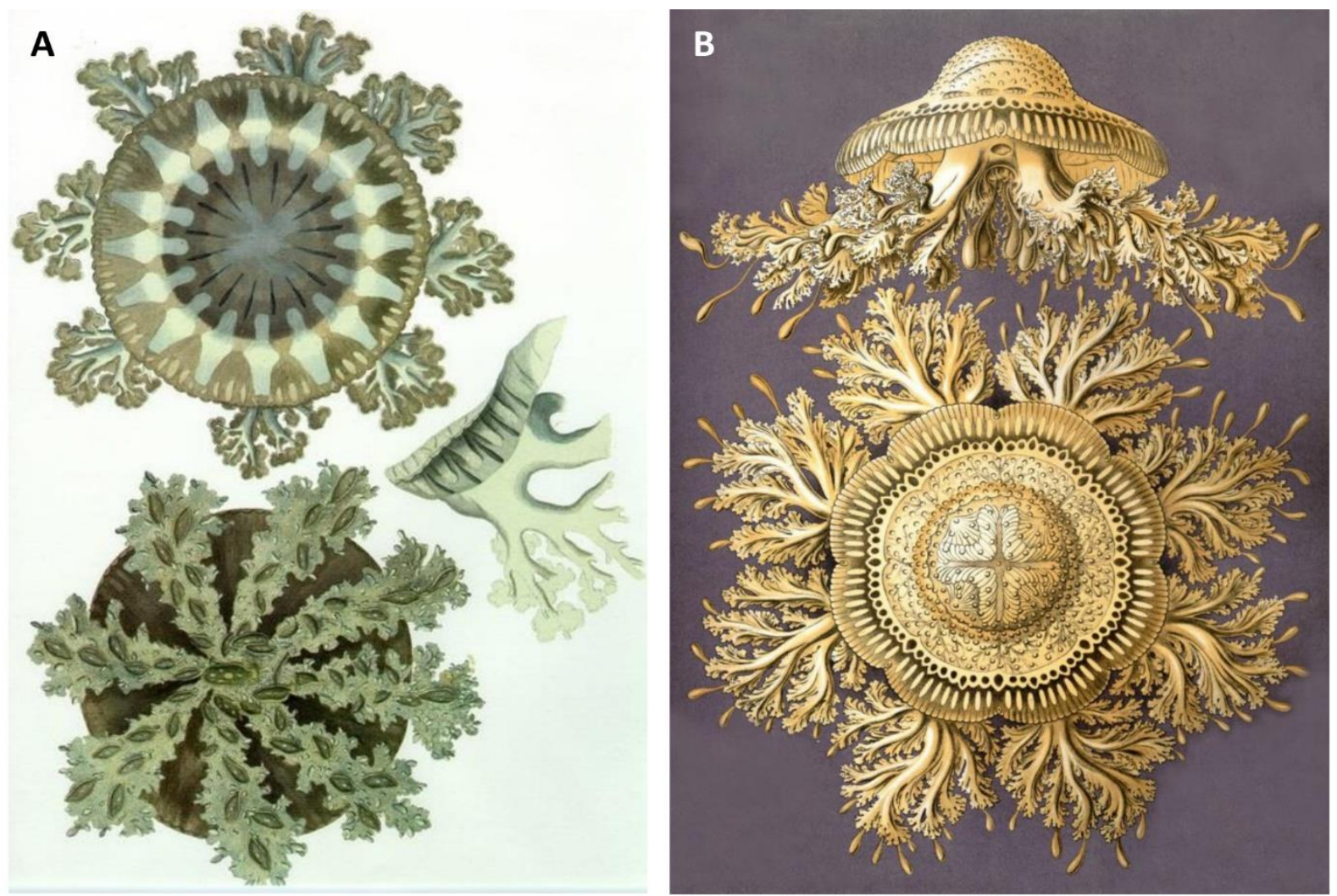

Fig 5 The morphological features of Cassiopea andromeda $(\mathbf{A})$ and Toreuma bellagemma $(\mathbf{B})$ on their original illustrations [by Forskål (1775: Tab. 31) and Haeckel (1904: Tafel 28) respectively]. 
remarkable natural shapes of this kind of medusae could be applied in decorating different materials such as fabrics, ceramics etc. in various industries; for example, printed fabric products with Haeckel's original illustrations of T. bellagemma are already available in the market (authors' observations). Especially, $C$. andromeda is an ecologically important creature as well. They were observed to be predated by Siganus fish species during the sample collection of the present study.

\section{ACKNOWLEDGEMENT}

This study was financially supported by National Science Foundation (NSF) of Sri Lanka under the grant: RG/2016/OMR/01.

\section{REFERENCES}

AZA, Aquatic Invertebrate TAG 2013. Jellyfish Care Manual. Association of Zoos and Aquariums, Silver Spring, MD, 79 p.

Browne, E.T. 1916. Notes on some jelly-fishes from Okhamandal in Kattiawar, collected by Mr. James Hornell in 1904-5. Report to the Government of Baroda on the Marine Zoology of Okhamandal in Kattiawar, Part II: $151-155$.

Çevik, C., I.L. Erkol \& B. Toklu 2006. A new record of an alien jellyfish from the Levantine coast of Turkey - Cassiopea andromeda (Forsskål, 1775) [Cnidaria: Scyphozoa: Rhizostomeae]. Aquatic Invasions 1(3): 196-197. https://doi.org/10. 3391/ai.2006.1.3.18

Fernando, M. 2006. Coral associated invertebrates: An overview of the current taxonomic status. In: The Fauna of Sri Lanka, Section 3: Status of Marine Fauna in Sri Lanka (C.N.B. Bambaradeniya ed), pp. 259-273. IUCN-The World Conservation Union.

Forskål, P. 1775. Descriptiones animalium, avium, amphibiorum, piscium, insectorum, vermium: quae in itinere orientali observavit. ex officina Mölleri, 224 p. https://doi.org /10.5962/bhl.title. 2154

Galil, B.S., E. Spanier \& W.W. Ferguson 1990. The Scyphomedusae of the Mediterranean coast of Israel, including two Lessepsian migrants new to the Mediterranean. Zoologische Mededelingen 64(7): 95-105.
Gall, L. 2020. Invertebrate Zoology Division, Yale Peabody Museum. Yale University Peabody Museum. Occurrence dataset https://doi.org/10.15468/0lkr3w accessed via GBIF.org (accessed on 24 July 2020).

Gülşahin, N. \& A.N. Tarkan 2012. Occurrence of the alien jellyfish Cassiopea andromeda (Scyphozoa: Rhizostomeae: Cassiopeidae) in Hisarönü Bay, Muğla, Turkey. Biharean Biologist 6(2): 132-133.

Haeckel, E. 1879. Das System der Medusen: Erster Theil einer Monographie der Medusen. Gustav Fischer, Jena, 81 p.

Haeckel, E. 1883. Indische Reisebriefe. Berlin, Paetel, 356 p. https://doi.org/10.5962/bhl.title .33939

Haeckel, E. 1904. Kuntsformen der Natur. Bibliographisches Institut, Leipzig and Vienna.

Heins, A., T. Glatzel \& S. Holst 2015. Revised descriptions of the nematocysts and the asexual reproduction modes of the scyphozoan jellyfish Cassiopea andromeda (Forskål, 1775). Zoomorphol 134: 351-366. https://doi.org/10.1007/s00435-015-0263-x

Holland, B.S., M.N. Dawson, G.L. Crow \& D.K. Hofmann 2004. Global phylogeography of Cassiopea (Scyphozoa: Rhizostomeae): molecular evidence for cryptic species and multiple invasions of the Hawaiian Islands. Marine Biology 145: 1119-1128. https:// doi.org/10.1007/s00227-004-1409-4

Hsieh, Y.H.P., F.M. Leong \& J. Rudloe 2001. Jellyfish as food. Hydrobiologia 451: 11-17. https://doi.org/10.1007/978-94-010-0722-1_2

Hummelinck, P.W. 1968. Caribbean Scyphomedusae of the genus Cassiopea. Studies of the Fauna of Curaçao and Caribbean Islands 25(1): 1-57.

Karunarathne, K.D. \& M.D.S.T. de Croos 2020a. A new species of box jellyfish, Carybdea wayamba sp. nov. (Cnidaria: Scyphozoa: Cubomedusae: Carybdeidae) from Sri Lanka. Plankton and Benthos Research (in press).

Karunarathne, K.D. \& M.D.S.T. de Croos 2020b. First records of three cepheid jellyfish species from Sri Lanka with redescription of the genus Marivagia Galil and Gershwin, 2010 (Cnidaria: Scyphozoa: Rhizostomeae: Cepheidae). Sri Lanka Journal of Aquatic Sciences 25(2): 45-55.

Katsanevakis, S. 2011. Rapid assessment of the marine alien megabiota in the shallow coastal 
waters of the Greek islands, Paros and Antiparos, Aegean Sea. Aquatic Invasions 6(1): 133-137. https://doi.org/10.3391/ai.201 1.6.S1.030

Kimor, B. 1973. Plankton Relations of the Red Sea, Persian Gulf and Arabian Sea. In: The biology of the Indian Ocean. Ecological Studies (Analysis and Synthesis), vol 3 (B. Zeitzschel \& S.A. Gerlach eds), pp. 221-232. Springer, Berlin, Heidelberg. https://doi.org/ 10.1007/978-3-642-65468-8_16

Kramp, P.L. 1961. Synopsis of the medusae of the world. Journal of the Marine Biological Association of the United Kingdom 40: 7 469. https://doi.org/10.1017/S002531540000 7347

Kramp, P.L. 1965. The Hydromedusae of the Pacific and Indian Oceans. Dana-Report 68: $1-162$.

Lampert, K.P. 2016. Cassiopea and Its Zooxanthellae. In: The Cnidaria, Past, Present and Future (S. Goffredo \& Z. Dubinsky eds), pp. 415-423. Springer, Cham. https://doi.org/10.1007/978-3-319-313054_26

Lampert, K.P., P. Bürger, S. Striewski \& R. Tollrian 2012. Lack of association between color morphs of the Jellyfish Cassiopea andromeda and zooxanthella clade. Marine Ecology 33(3): 364-369. https://doi.org/ 10.1111/j.1439-0485.2011.00488.x

Mayer, A.G. 1910. Medusae of the World, Scyphomedusae, vol. III. Carnegie Institution, Washington DC, 735 p. https://doi.org/10.5962/bhl.title.159245

McKenzie, M.R., M.A. Templeman \& M.J. Kingsford 2020. Detecting effects of herbicide runoff: the use of Cassiopea maremetens as a biomonitor to hexazinone. Aquatic Toxicology 221. https://doi.org/ 10.1016/j.aquatox.2020.105442

Menon, M.G.K. 1930. The Scyphomedusae of Madras and the neighbouring coast. Bulletin of Madras Government Museum; Natural History Section 3(1): 1-28.

Menon, M.G.K. 1936. Scyphomedusae of Krusadai Island. Bulletin of Madras Government Museum; Natural History Section 3(1): 1-9.

Morandini, A.C., S.N. Stampar, M.M. Maronna \& F.L. Da Silveira 2017. All non-indigenous species were introduced recently? The case study of Cassiopea (Cnidaria: Scyphozoa) in Brazilian waters. Journal of the Marine Biological Association of the United
Kingdom 97(2): 321-328. https://doi.org/ $10.1017 /$ S0025315416000400

Natural History Museum 2020. Natural History Museum (London) Collection Specimens. Occurrence dataset https://doi.org/10.5519 /0002965 accessed via GBIF.org (accessed on 24 July 2020).

Ohta, N., M. Sato, K. Ushida, M. Kokubo, T. Baba, K. Taniguchi, M. Urai, K. Kihira \& J. Mochida 2009. Jellyfish mucin may have potential disease-modifying effects on osteoarthritis. BMC Biotechnology 9: 98. https://doi.org/10.1186/1472-6750-9-98

Omori, M. \& E. Nakono 2001. Jellyfish fisheries in Southeast Asia. Hydrobiologia 451: 19-26. https://doi.org/10.1007/978-94-010-0722-1_3

Özgür, E. \& B. Öztürk 2008. A population of the alien jellyfish, Cassiopea andromeda (Forsskål, 1775) [Cnidaria: Scyphozoa: Rhizostomea] in the Ölüdeniz Lagoon, Turkey. Aquatic Invasions 3(4): 423-428. https://doi.org/10.3391/ai.2008.3.4.8

Prasade, A., P. Nagale \& D. Apte 2016. Cassiopea andromeda (Forsskål, 1775) in the Gulf of Kutch, India: initial discovery of the scyphistoma, and a record of the medusa in nearly a century. Marine Biodiversity Records 9: 36. https://doi.org/10.1186/ s41200-016-0031-8

Purcell, J.E. \& M.N. Arai 2001. Interactions of pelagic cnidarians and ctenophores with fish: a review. Hydrobiologia 451: 27-44. https://doi.org/10.1007/978-94-010-0722-1_4

Purcell, J.E., S. Uye \& W.T. Lo 2007. Anthropogenic causes of jellyfish blooms and their direct consequences for humans: a review. Marine Ecology Progress Series 350: 153-174. https://doi.org/10.3354/meps07093

Rahat, M. \& O. Adar 1980. Effect of symbiotic zooxanthellae and temperature on budding and strobilation in Cassiopeia andromeda (Eschscholz). The Biological Bulletin 159(2): 394-401. https://doi.org/10.2307/1541102

Rao, H.S. 1931. Notes on Scyphomedusae in the Indian museum. Records of Indian Museum 33: 25-62.

Richardson, A.J., A. Bakun, G.C. Hays \& M.J. Gibbons 2009. The jellyfish joyride: causes, consequences and management responses to a more gelatinous future. Trends in Ecology and Evolution 24(6): 312-322. https://doi. org/10.1016/j.tree.2009.01.010

Schäffer, W. 1955. Eine Qualle aus dem Indischen Ozean in der Agais. Natur Volk 85: 241-245. 
Krishan D. Karunarathne et al.

Schembri, P.J., A. Deidun \& P.J. Vella 2010. First record of Cassiopea andromeda (Scyphozoa : Rhizostomeae: Cassiopeidae) from the central Mediterranean Sea. Marine Biodiversity Records 3(6): 1-2. https:// doi.org/10.1017/S1755267209990625

Shenoi, S.S.C., P.K. Saji \& A.M. Almeida 1999. Near-surface circulation and kinetic energy in the tropical Indian Ocean derived from Lagrangian drifters. Journal of Marine Research 57(6): 885-907. https://doi.org/ $10.1357 / 002224099321514088$

Stiasny, G. 1931. Die Rhizostomeen-Sammlung des British Museum (Natural History); in London. Zoologische Mededelingen 14: 137178.

Sugahara, T., M. Ueno, Y. Goto, R. Shiraishi, M. Doi, K. Akiyama \& S. Yamauchi 2006. Immunostimulation effect of jellyfish collagen. Bioscience, Biotechnology, and Biochemistry 70(9): 2131-2137. https://doi.or g/10.1271/bbb.60076

Thiel, M.E. 1975. Bemerkungen zur Systematik der Gattung Cassiopea (Cepheida,
Scyphomedusae). Mitteilungen aus dem Hamburgischen Zoologischen Museum und Institut 72: 25-46.

Venkataraman, K., C. Raghunathan, R. Raghuraman \& C.R. Sreeraj 2012. Marine Biodiversity. Published by the Director, Zoological Survey India, and Kolkata, 164 p.

WoRMS Editorial Board 2020. World Register of Marine Species. Available at: http:// www.marinespecies.org (accessed on 24 July 2020).

Zenetos, A., M.E. Çinar, M.A. PancucciPapadopoulou, J.G. Harmelin, G. Furnari \& F. Andaloro 2005. Annotated list of marine alien species in the Mediterranean with records of the worst invasive species. Mediterranean Marine Science 6(2): 63-118. https://doi.org/10.12681/mms.186

Zenetos, A., S. Katsanevakis, D. Poursanidis, F. Crocetta, D. Damalas \& G. Apostolopoulos 2011. Marine alien species in Greek Seas: additions and amendments by 2010 . Mediterranean Marine Science 12(1): 95120. https://doi.org/10.12681/mms.55 